\title{
Performance Comparison between Sequential Command SPWM and MLI-NPC in Multi-MW drives for WECSs
}

\author{
K. ElShawarby, A. Di Gerlando, G. M. Foglia, R. Perini \\ POLITECNICO DI MILANO \\ Via La Masa 34 \\ 20156 Milano, Italy \\ Phone: +39 (02) 23993722
}

Email: \{khaled.elshawarby, antonino.digerlando, gianmaria.foglia, roberto.perini $\} @$ polimi.it

\section{Keywords}

$\ll$ Sequential Command $\gg, \ll$ Series Connected Converters $\gg, \ll$ Multi-modular machines $\gg, \ll$ MLINPC converter $\gg, \ll$ Harmonic elimination $\gg, \ll$ Converter Losses $\gg$

\begin{abstract}
The paper presents a comparison between two energy conversion methods for a multi-modular axial flux machine used for wind energy conversion systems, namely: Sequential Command for series connected two-level converters and a Multilevel NPC converter. The Sequential Command is the shift of the carrier signals for the neighbouring two-level converters connected in series in order to minimize harmonic distortion. A phase disposition PWM is used for Multilevel NPC since it offers much lower harmonic content. The comparison takes into account both harmonic content of current and torque waveforms and losses in the converter.
\end{abstract}

\section{Introduction}

In recent years, Axial Flux (AF) Permanent Magnet Synchronous Generators (PMSGs) have gained more popularity compared to Radial Flux (RF) PMSGs particularly for low speed drives such as wind energy conversion systems (WECSs). This is mainly due to its higher power density and high torque to weight ratio [1]. A Multi-Modular AFPMSG is proposed in [2], where such a configuration allows higher power output with same radial length and more reliability and redundancy due to the absence of magnetic mutual coupling between modules.

The WECSs with Sequential Command was proposed in [3]. The conversion system involves the connection of a two-level IGBT converter with each module of the machine. All modules are connected in parallel on the DC side. The carrier signals of the neighbouring converters are shifted according to suited angles obtained by an analytical approach in order to eliminate the harmonics in the overall electromagnetic torque and DC side current.

An alternative for multiphase machines energy conversion is the use of Multi-Level Inverters (MLI). In fact, the MLIs are preferred to two-level converters because of their lower harmonic injection and lower torque ripples for the same switching frequency [4]. However, they have higher number of switches and a complex gating circuitry that increases the overall complexity of the system.

In the present paper, a comparison between Sequential Command for two-level converters and a Multilevel converter is presented. As for the generator, a four module AFPMSG is considered. As for the converters, two simple and common configurations have been chosen for the comparison, namely: four two-level (2L) converters connected in series with Sequential Command (Figure 1a) where each converter is connected to a module of the machine. The other configuration considers the series connection of the four module 
AFPMSG connected to a five-level (5L) NPC [5] (Figure 2a, b). The modulation technique used for the 5L NPC is the phase disposition (PD) PWM since it has the lowest harmonic content compared to phase opposition disposition (POD) PWM and alternative phase opposition disposition (APOD) PWM [6, 7].

The paper is divided as follows: Section II presents the WECS connected to two conversion schemes. The data of a module of the machine is reported as well. Section III compares the performances of the two conversion schemes in terms of harmonic content and THD\% of both the ac current and the electromagnetic torque obtained from simulations. Finally Section IV compares the converter losses in both schemes by means of an accurate model that calculate the losses in simulations. An overall comparison between the two schemes is presented.

\section{Wind Energy Conversion Systems Under Study}

The WECS considered in this paper is a four-module AFPMSG directly driven by the wind turbine (WT). The machine data for one module are reported in Table I. Each module is connected to a $1.6 \mathrm{kV}$ dedicated two-level converter and all converters are connected in series on the DC side as highlighted in Figure 1a. The modulation is SPWM with sequential command in which the carrier signals of the converters are shifted among them such that each carrier phase angle is $\psi_{c_{1}}=0^{\circ}, \psi_{c_{2}}=90^{\circ}, \psi_{c_{3}}=180^{\circ}$ and $\psi_{c_{4}}=270^{\circ}$ as shown in Figure 1b. The control of individual dc bus voltage for series connected converters was discussed in deep in [8].

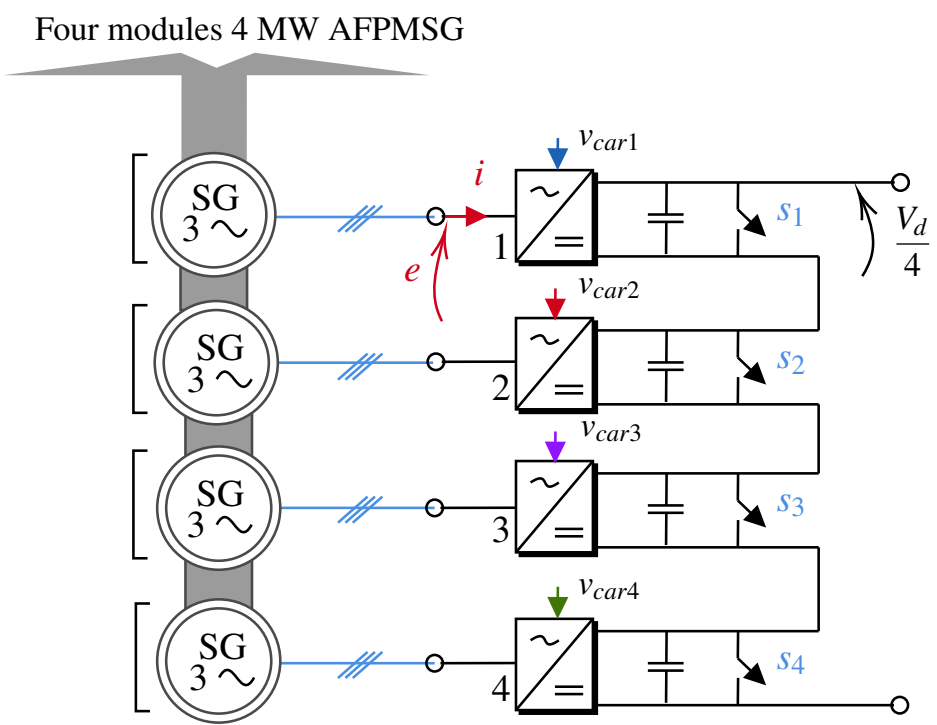

(a)

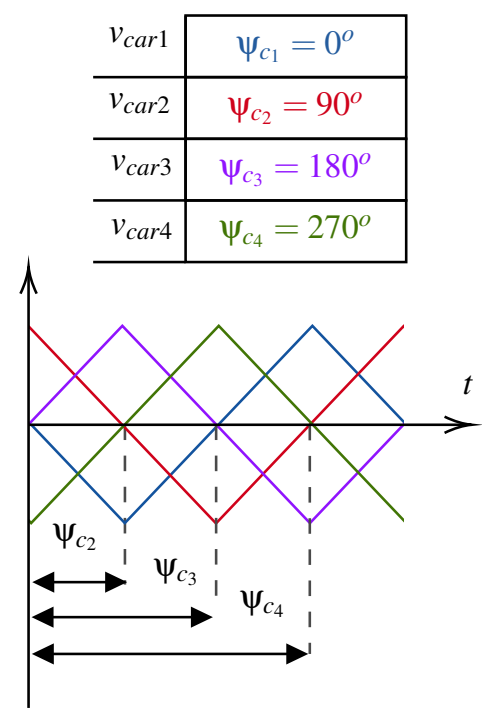

(b)

Fig. 1: a) Schematic of the modular direct-drive axial-flux PMSG under study. Each module of the machine is connected to a two-level converter. All converters are connected in series on the dc side. b) the carrier signals for the four converters are shifted from each other by $90^{\circ}$.

Table I: single module axial flux permanent magnet machine nameplate data

\begin{tabular}{|l|c|}
\hline$P_{n}[\mathrm{MW}], I_{n}[\mathrm{~A}]$, Rated Speed $\Omega_{n}[\mathrm{rpm}]$ & $1.0,650,17$ \\
\hline Rated frequency $f_{\text {rated }}[\mathrm{Hz}], \mathrm{N}$. of poles $p$ & $14.73,104$ \\
\hline $\begin{array}{l}\text { Line to neutral EMF at rated speed [V] } \\
\text { (sinusoidal waveform) }\end{array}$ & 509 \\
\hline Phase resistance $R[\mathrm{~m} \Omega]$ & 16.15 \\
\hline Synchronous inductance $(d, q$ axes) $L[\mathrm{mH}]$ & 3.132 \\
\hline Rotor ext. diameter $[\mathrm{m}]$, Axial length $[\mathrm{m}]$ & $5.00,0.603$ \\
\hline
\end{tabular}




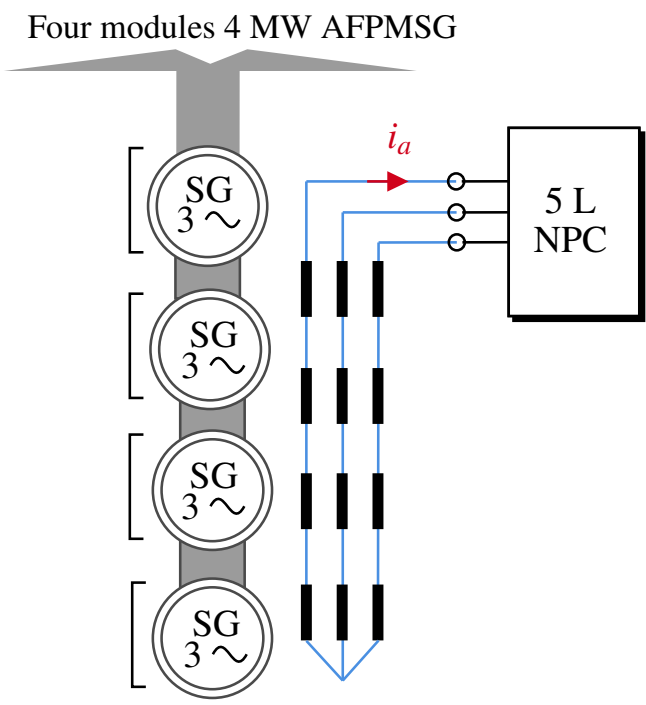

(a)

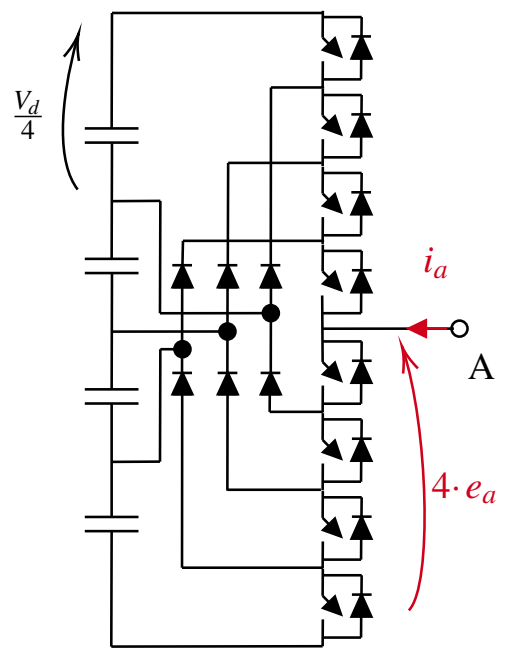

(b)

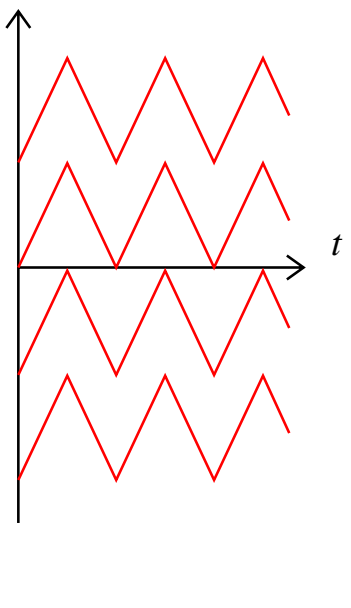

(c)

Fig. 2: a) Schematic of the modular direct-driven axial-flux series connected PMSG under study connected to 5L NPC. b) one leg of the 5L NPC. c) PD-PWM modulation.

The SPWM with sequential command conversion system is compared with a 5L NPC where the PD PWM modulation is used as depicted in Figure 2 with the AFPMSG module windings connected in series in order to elevate the line to neutral EMF to four times that of each module.

The total DC voltage $V_{d}$ is kept the same for both configurations at $6.4 \mathrm{kV}$. The total number of IGBTs are the same for both configurations and have the same reverse blocking voltage $\left(\frac{V_{d}}{4}\right)$. These considerations allow the use of the same switch for both configurations and having a meaningful comparison between the two configurations. The comparison deals with both harmonic content and total converter losses.

\section{Harmonic Content Comparison}

An approximated analytical expression for the electromagnetic torque and the dc bus voltage was developed in $[3,9]$, which shows the main harmonics in the torque and the dc voltage along with the dependencies of each harmonic on the shift angle of the carrier signal $\psi_{c_{\mu}}$ where $\mu$ is the module number (here, $\mu=1,2,3,4$ ). Such analytical approximated expression proved to be accurate for estimating both harmonic order and amplitudes for both the torque and dc voltage when compared with results of a Simulink model [3]. The choice $\psi_{c_{\mu}}=\left\{0^{0}, 90^{\circ}, 180^{\circ}\right.$, and $\left.270^{\circ}\right\}$ cancels the harmonics of the order $\left(h=m_{f} \pm 3,2 m_{f}, 3 m_{f} \pm 3\right.$ where $m_{f}$ is the frequency modulation ratio) and the least order harmonics left in the torque and voltage expressions is $4 m_{f}$. For this reason, such choice of the carriers signals shift achieves a much lower harmonic content than the normal SPWM where the least order harmonic is $m_{f}-3$ [9].

Both conversion systems presented in Section II are implemented in Matlab/Simulink. Each module of the machine is modeled by standard two-axis $d-q$ model of PMSM and the classical FOC is implemented, the machine is vector-controlled to operate in maximum torque-per-ampere (MTPA) conditions. It is assumed that the total DC bus voltage is kept constant by the grid side converter which is modeled as current-controlled source. The chosen $m_{f}$ is as low as 15 in order to minimize the switching losses.

Figures $3 \mathrm{a}, 4 \mathrm{a}$ and $5 \mathrm{a}$ show the four machine modules with the $2 \mathrm{~L}$ converters phase " $a$ " currents $\left(i_{a 1}, i_{a 2}, i_{a 3}, i_{a 4}\right)$, individual dc voltages $\left(v_{d 1}, v_{d 2}, v_{d 3}, v_{d 4}\right)$ as well as the torques of each module $\left(T_{e 1}, T_{e 2}, T_{e 3}, T_{e 4}\right)$ respectively at the rated frequency $f_{n}$. It is evident the shift of the harmonics via the Sequential Command of the converters in all waveforms.

Figures $3 b, 4 b$ and $5 b$ present the simulation results for both $2 \mathrm{~L}$ converters with sequential command and $5 \mathrm{~L}$ NPC at $f_{n}$. Table II shows the THD\% for the ac current, total dc voltage and total electromagnetic 
torque for both conversion systems. Some notes can be made:

- Fig. $3 \mathrm{~b}$ shows the ac current of one of the converter legs for both converter schemes $i_{a(2 L)}, i_{a(5 L)}$ where it can be seen that the harmonic content of the normal SPWM is higher than 5L NPC with PD PWM modulation; the same apparent from the values reported in table II;

- however, despite the higher harmonic content in the ac current, the harmonic content of the dc voltage and torque is considerably lower due to the sequential command and harmonic cancellation (Figs. $4 \mathrm{~b}$ and $5 b$ ).

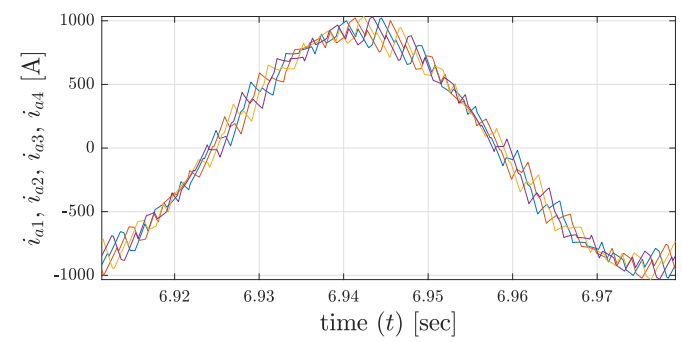

(a)

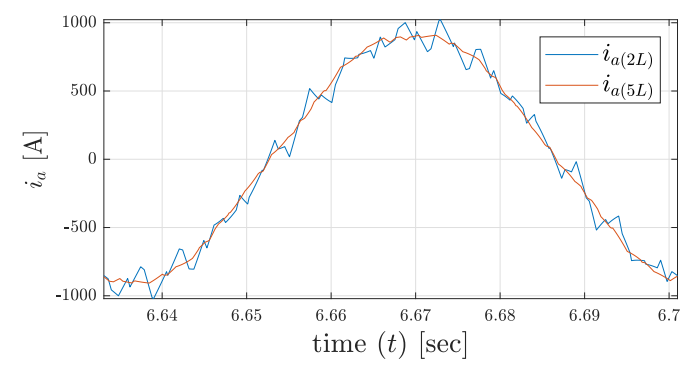

(b)

Fig. 3: (a) Four-module AFPMSG: phase $a$ AC currents of each of the four individual converters shifted by the sequential command (b) converter phase $a$ current for both 5L NPC and 2L converters waveforms at $f_{n}$ in which is apparent the harmonic content in the $2 \mathrm{~L}$ converters is higher than that of the 5L NPC.

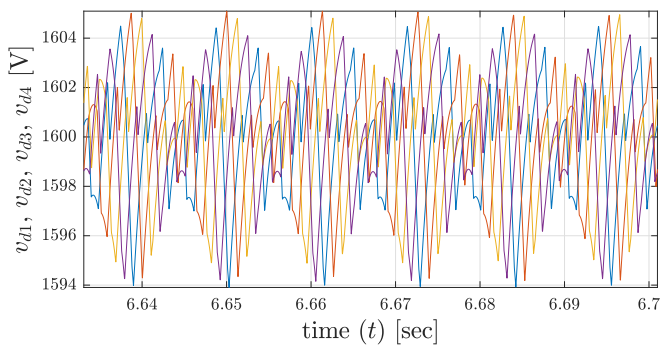

(a)

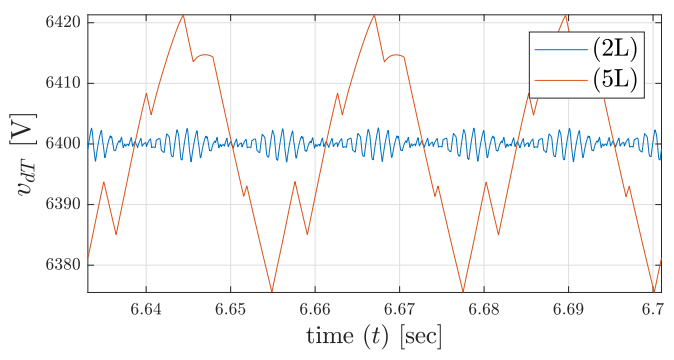

(b)

Fig. 4: (a) Four-module AFPMSG dc bus individual converter voltage shifted by the sequential command. (b) Total dc bus voltage for both 5L NPC and $2 \mathrm{~L}$ converters waveforms at $f_{n}$. Because of the sequential command, the harmonic content in the $2 \mathrm{~L}$ converters configuration is much lower than the $5 \mathrm{~L}$ NPC.

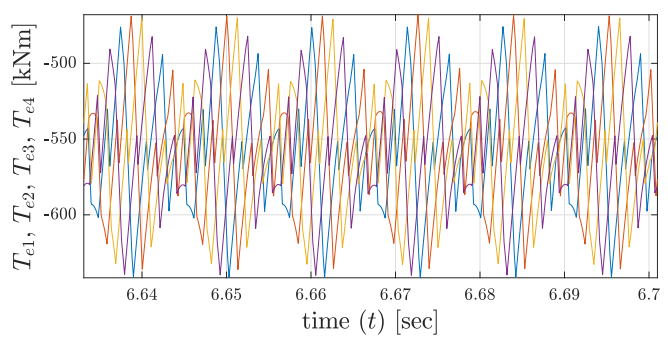

(a)

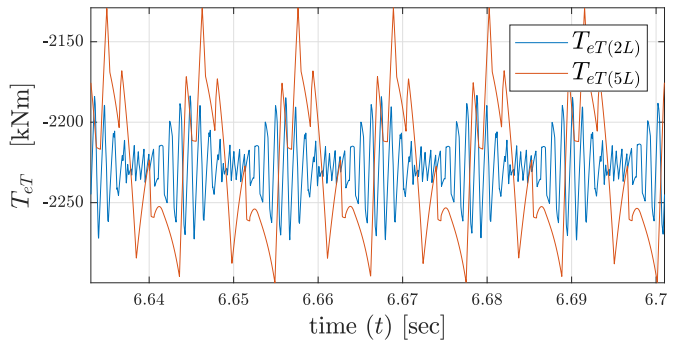

(b)

Fig. 5: (a) Four module AFPMSG individual electromagnetic torques shifted by the sequential command. (b) Total machine electromagnetic torque for both $5 \mathrm{~L}$ NPC and $2 \mathrm{~L}$ converters waveforms at $f_{n}$. Sequential Command 2L converters have much lower harmonics than the 5L NPC. 
Table II: A comparison between simulation results of the two conversion method: the four $2 \mathrm{~L}$ converters connected in series with Sequential Command and 5L NPC converter with PD PWM modulation for the harmonic content of the ac current, dc total voltage and total electromagnetic torque.

\begin{tabular}{|l|c|c|}
\hline & 2L converters with Sequential command & 5L NPC converter \\
\hline$\hat{I}_{a 1}[\mathrm{~A}]$ & 915 & 915 \\
\hline$T H D_{I_{a}} \%$ & 9.29 & 2.59 \\
\hline$V_{d T}[\mathrm{kV}]$ & 6.4 & 6.4 \\
\hline$T H D_{V_{d T}} \%$ & 0.02 & 0.38 \\
\hline$T_{e T}[\mathrm{kNm}]$ & 2228 & 2228 \\
\hline$T H D_{T_{e T}} \%$ & 1.08 & 2.62 \\
\hline
\end{tabular}

The simulations for both 5L NPC and the four 2L converters driving the 4MW four modules AFPMSG are repeated at different frequencies covering the frequency range. The power generation to the grid ranges between the cut-in speed (normally $0.3-0.35 \cdot \Omega_{n}$ ) up to the rated one $\Omega_{n}$. Since the ratio between DC bus voltage and the line to neutral EMF for both cases is the same $\left(\frac{V_{d}}{4}\right.$ and $E$ for the two level converter and $V_{d}$ and $4 \cdot E$ for the $5 \mathrm{~L} \mathrm{NPC}$ ) and the machine frequency is equal, the amplitude modulation index $m_{a}$ for both schemes is equal.

Figure 6 shows the simulation results for the THD\% of the ac current, dc total voltage and total torque for both $2 \mathrm{~L}$ converters and the 5L NPC. It can be seenthat or the ac current THD $\left(T H D_{I_{a}}\right) 6 \mathrm{a}$, the 5L NPC has a lower THD\% for the whole frequency range. However, focusing on both the dc voltage and torque THD\% $\left(T H D_{V_{d T}}, T H D_{T_{e T}}\right)$ in figures $6 \mathrm{~b}$ and $6 \mathrm{c}$, the effect of sequential command for the $2 \mathrm{~L}$ converters can be seen as it has lower THD\% for almost all the frequency range.
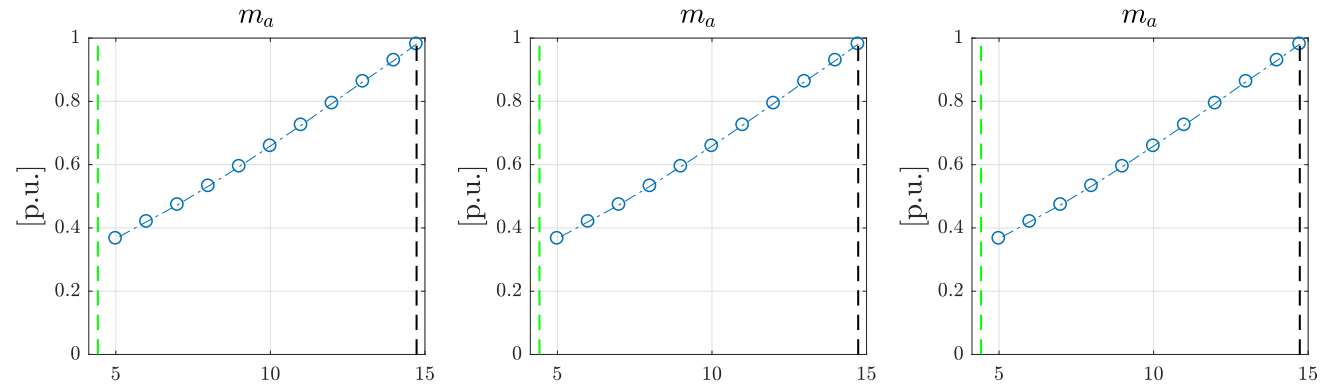

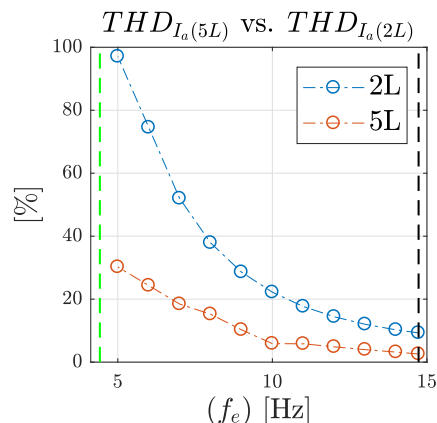

(a)

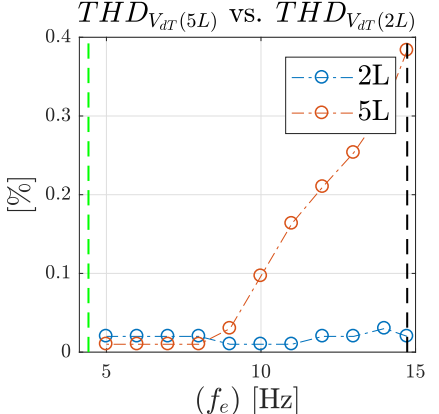

(b)

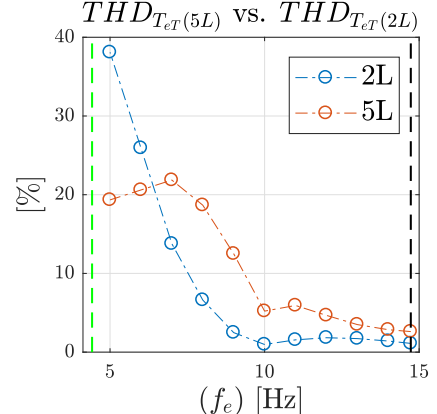

(c)

Fig. 6: THD\% of several quantities, across the overall frequency range, for $5 \mathrm{~L}$ and $2 \mathrm{~L}$ converters (a) phase $a$ current $T H D_{I_{a c}}$. (b) total dc voltage $T H D_{V_{d T}}$ (c) the total machine torque $T H D_{T_{e T}}$ 


\section{Converter Losses Comparison}

Starting from a built-in Simulink model [10], an accurate model for the converter losses estimation is realized in Matlab/Simulink where the losses calculation is done every simulation instant $t_{x}$. A heatsink is designed as well using Simscape blocks from the thermal foundation library to build a two-cell thermal network based on the thermal capacitances (case and heat sink) and resistances (case-to-sink and sink-to-ambient) [11].

Both converters are comprised of IGBTs modules, made by transistors and free wheeling diodes. As for the diode losses, they are split into reverse recovery loss $\left(P_{r r, D}\right)$ and conduction losses $\left(P_{o n, D}\right)$. They can be expressed as:

$$
\left\{\begin{aligned}
\left.P_{r r, D}\left(T_{J}(t), t\right)\right|_{t_{x}} & =\left.E_{r r-D}\left(T_{J}(t), i_{f, D}(t), u_{f, D}(t)\right)\right|_{t_{x}} \cdot f_{s w} \\
\left.P_{o n, D}\right|_{t_{x}} & =\left.\left.u_{f, D}(t)\left(i_{f, D}(t), T_{J}(t)\right)\right|_{t_{x}} \cdot i_{f, D}(t)\right|_{t_{x}}
\end{aligned}\right.
$$

where, $E_{r r-D}$ is the reverse recovery energy loss which is calculated via 3-D table (based on the specification found in the switch manufacturer's datasheets) that relies on the pre-switching value of the current flowing in to the diode $i_{f, D}(t)$, post-switching value of the voltage across the device $u_{f, D}(t)$, and the junction temperature $T_{J}(t)$. The on-state voltage $u_{f, D}(t)$ is evaluated by a 2-D look up table from the values of $i_{f, D}(t)$ and $T_{J}(t)$.

As for the transistor losses, they are split into switching on and off losses $\left(P_{s w(o n), T}, P_{s w(o f f), T}\right)$ and conduction losses $\left(P_{o n, T}\right)$, which can be expressed as:

$$
\left\{\begin{array}{c}
\left.P_{s w(o n), T}\right|_{t_{x}}=\left.E_{s w(o n), T}\left(T_{J}(t), i_{c, T}(t), u_{c e, T}(t)\right)\right|_{t_{x}} \cdot f_{s w} \\
P_{s w(o f f),\left.T\right|_{t_{x}}}=\left.E_{s w(o f f), T}\left(T_{J}(t), i_{c, T}(t), u_{c e, T}(t)\right)\right|_{t_{x}} \cdot f_{s w} \\
\left.P_{o n, T}\right|_{t_{x}}=\left.\left.u_{c e, T}(t)\left(i_{c, T}(t), T_{J}(t)\right)\right|_{t_{x}} \cdot i_{c, T}(t)\right|_{t_{x}}
\end{array}\right.
$$

where, $E_{S w(o n), T}$ and $E_{S w(o f f), T}$ are turn-on, turn-off switching energy losses respectively; they are determined by the help of a 3-D lookup table whose inputs are pre-switching value of the voltage across the transistor $u_{c e, T}(t)$, post-switching value of the current flowing into it $i_{c, T}(t)$, and $T_{J}(t)$. The saturation voltage $\left(u_{c e, T}(t)\right)$ across the IGBT it is determined via a 2-D lookup table from the values of $i_{c, T}(t)$ and $T_{J}(t)$. All the power losses are then injected into the thermal network in order to emulate the behaviour of a real system and find the new value of $T_{J}$.

All the values needed to construct the 2-D and 3-D lookup tables (used to determine the losses) are extracted from the switch manufacturer's datasheet. A numerical low pass filter is used to reconstruct the continuous switching power losses from the discrete switching power losses. Finally, the total losses of a converter are given by the summation of the losses of total number of diodes and IGBTs.

Since in both configurations the rated current that flows into converter legs is the same (915 A) and the partial voltage across each switch is also the same $(1.6 \mathrm{kV})$, the switch chosen for both configurations is the same whose data is reported in Table III. 
Table III: High Power Switches rated data: Infineon FZ1200R17HP4

\begin{tabular}{|l|c|}
\hline Collector Emitter Voltage $V_{C E S}[\mathrm{~V}]$ & 1700 \\
\hline Collector Current $I_{C n}[\mathrm{~A}] @ T_{c}=100{ }^{\circ} \mathrm{C}$ & 1200 \\
\hline Turn-on, turn-off switching loss $E_{O N}, E_{O F F}[\mathrm{~mJ}]$ & 365,415 \\
\hline Diode forward voltage $V_{F}[\mathrm{~V}] @ I_{F}=1200 \mathrm{~A}$ & 1.90 \\
\hline Maximum Power Dissipation @ $T_{v j}=175^{\circ} \mathrm{C}[\mathrm{kW}]$ & 7.8 \\
\hline \multicolumn{2}{|c|}{ Junction to Case Thermal Resistance } \\
\hline for IGBT $R_{t h J C_{I}}$ and diodes $R_{t h J C_{D}}[\mathrm{~K} / \mathrm{kW}]$ & $19.0,32.0$ \\
\hline \multicolumn{2}{|c|}{ Case to Heat-sink Thermal Resistance } \\
\hline for IGBT $R_{t h C H_{I}}$ and diodes $R_{t h C H_{D}}[\mathrm{~K} / \mathrm{kW}]$ & $10.0,11.0$ \\
\hline
\end{tabular}

\section{Converter Losses at $f_{n}$}

The diodes in 5L NPC serve two purposes: free-wheeling diodes (FWD) for the IGBTs and the clamping diodes. Thus a comparison between the losses in FWD diodes per leg for the $5 \mathrm{~L}$ and four $2 \mathrm{~L}$ converters are presented in figure 7a. It can be seen the losses in the diodes in the $2 \mathrm{~L}$ converters are higher than those in 5L NPC. This is because the conduction patterns for the four $2 \mathrm{~L}$ converters under SPWM have more switching instants and longer conduction periods compared to those in 5LNPC. Figure $7 \mathrm{~b}$ reports the conduction losses in the clamping diodes per leg of the 5L NPC while figure 7c shows the total losses in all diodes per leg in both configurations. Despite the presence of clamping diodes in the 5L NPC, the losses in the diodes for the four $2 \mathrm{~L}$ converters are higher.

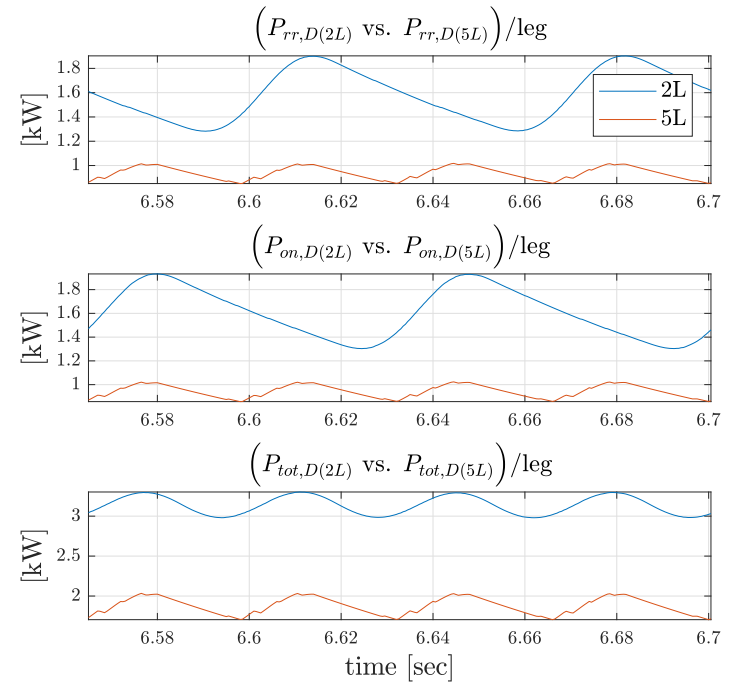

(a)

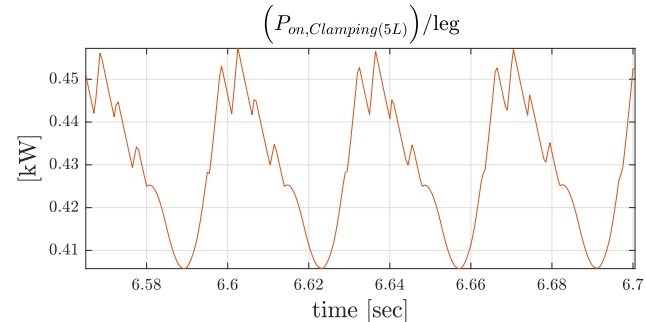

(b)

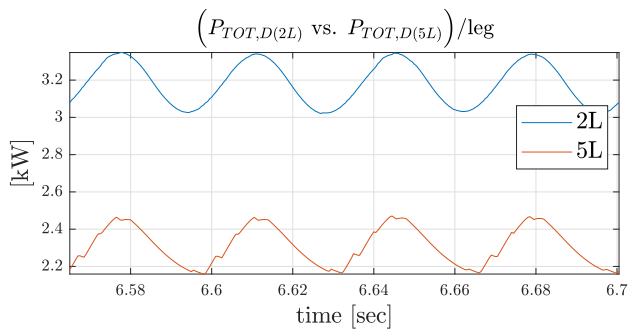

(c)

Fig. 7: a) FWD diodes reverse recovery, conduction and total losses for both $5 \mathrm{~L}$ and $2 \mathrm{~L}$ converters. b) Conduction losses of the clamping diodes in the $5 \mathrm{~L}$ converter at $f_{n}$. c) Total losses for the total diodes in both $5 \mathrm{~L}$ and $2 \mathrm{~L}$ converters at $f_{n}$

Similarly the losses in the IGBTs for both configurations are presented in figure 8. It can be seen that the conduction losses for both configurations is more or less the same which is because the same current passes through the switch and the total number of IGBTs are the same. As for the switching losses, IGBTs in 2L converters have higher switching instants than their counterparts in 5L NPC under PD PWM.

By summing all losses in diodes and IGBTs, the total losses/leg can be obtained in figure 8c where the average losses for the group $2 \mathrm{~L}$ converters and $5 \mathrm{~L}$ converter are $3.8 \mathrm{~kW}$ and $2.92 \mathrm{~kW}$ respectively. Therefore, the maximum losses (at $f_{n}$ ) in the $5 \mathrm{~L}$ converter is $24 \%$ lower than the group of $2 \mathrm{~L}$ converters. 

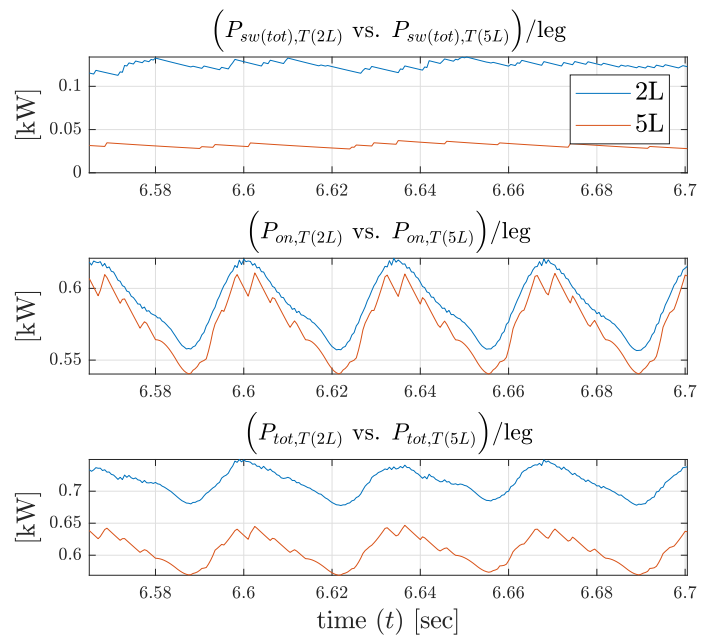

(a)

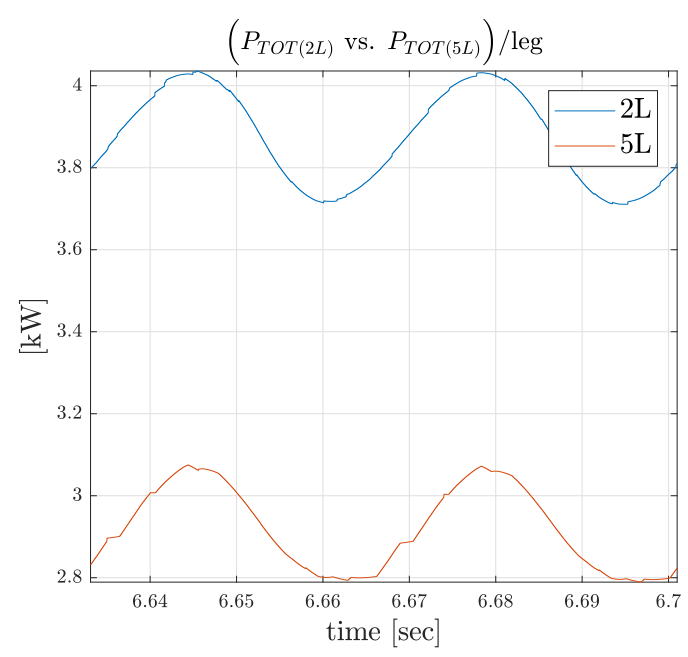

(b)

Fig. 8: a) IGBT switching, conduction and total losses for both $5 \mathrm{~L}$ and $2 \mathrm{~L}$ converters at $f_{n}$. b) Total converter losses per leg for both $5 \mathrm{~L}$ and $2 \mathrm{~L}$ converters at $f_{n}$.

\section{Converter Losses for Overall Frequency Range}

The simulations are repeated at different frequencies across the frequency range. The conduction, reverse recovery losses of the FWDs for both $5 \mathrm{~L}$ and $2 \mathrm{~L}$ converters along with the conduction losses of the clamping diodes in the 5L converter are shown in figure 9a. The behaviour of the losses in FWDs for the two level converter is always higher than the losses in 5L NPC. Moreover, for the 5L NPC scheme, as the modulation index decreases the number of levels utilized decreases. In fact when $m_{a}$ drops below 0.5 , the losses in the FWDs become zero.

Figure $9 \mathrm{~b}$ shows the losses for IGBTs for $5 \mathrm{~L}$ and $2 \mathrm{~L}$ converters. As mentioned earlier, the conduction losses in $5 \mathrm{~L}$ converter is more or less equal to those of $2 \mathrm{~L}$ converters since the current flowing in the switches are exactly the same for both configurations. While, the switching losses are lower in case of the 5L NPC and when $m_{a}$ drops below 0.5 and the number of levels utilized decreases the switching losses in the $5 \mathrm{~L}$ NPC becomes much higher than those of the $2 \mathrm{~L}$ converters.

Figure $9 \mathrm{c}$ shows the total diode losses along with total IGBTs losses for both converter topologies. Figure 10 shows the total converter losses for both topologies across the machine frequency range where it can be seen that the losses in the $2 \mathrm{~L}$ converter are always higher than the $5 \mathrm{~L}$ converters losses for the overall frequency range.

Some conclusions can be made comparing both the performance and the losses for both topologies:

- the losses in the series connected $2 \mathrm{~L}$ converters configuration is relatively higher compared to the 5L NPC considering the operation at different frequencies across the frequency range. However, it was shown in the previous section the superiority of the $2 \mathrm{~L}$ converters with sequential command in terms of lower harmonic content in the overall torque and dc voltage;

- furthermore, the SPWM modulation and gating circuits for 5L converter is more complicated compared to the simple SPWM modulation of $2 \mathrm{~L}$ converter [12];

- finally, the series configuration provides a higher redundancy and reliability since, in the event of a converter failure, switch $s \mu$ (in figure 1) shorts out the faulted converter and the rest of the converters can still transfer power at lower level. Moreover, Sequential Command can be reprogrammed for the new configuration in order to have lower THD\%. For example in case of one converter failure, the lowest THD $\%$ can be achieved by adopting $\psi_{c \mu}=\left\{0^{0}, 120^{\circ}, 240^{\circ}\right\}$. 

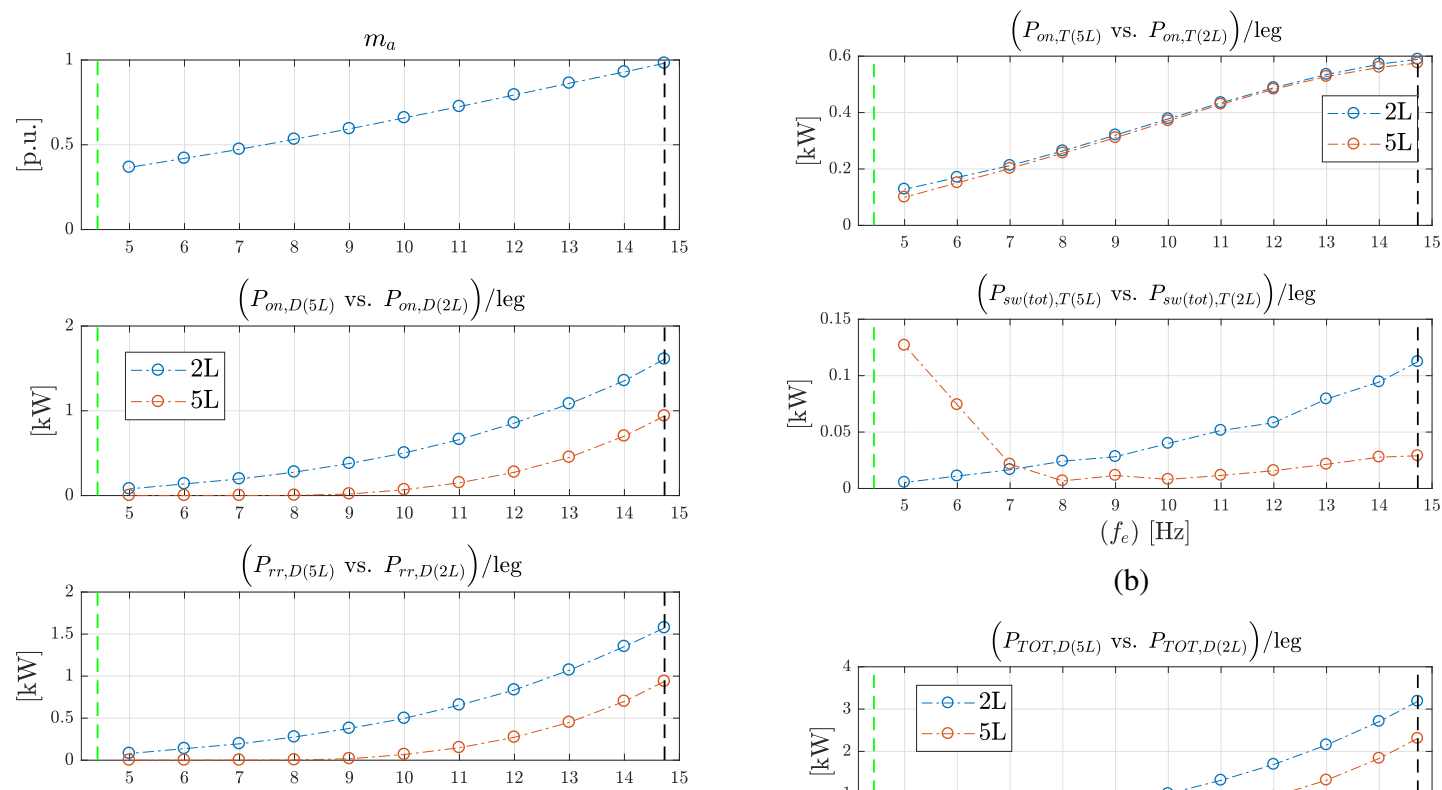

(b)
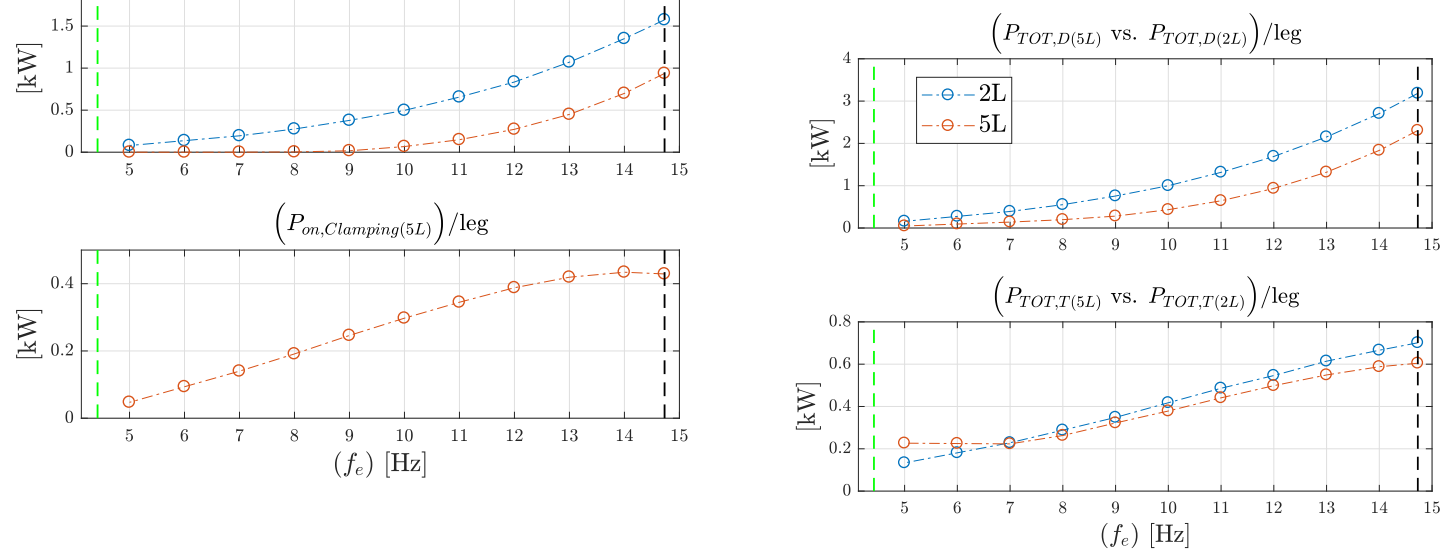

(a)

(c)

Fig. 9: a) FWD diodes reverse recovery, conduction losses for both $5 \mathrm{~L}$ and $2 \mathrm{~L}$ converters and conduction losses for the clamping diodes confronted with $m_{a}$ across the frequency range; b) IGBT conduction and switching losses for both $5 \mathrm{~L}$ and $2 \mathrm{~L}$ converters over the frequency range. c) Total losses in IGBTs and all diodes for both $5 \mathrm{~L}$ and $2 \mathrm{~L}$ converters over the frequency range.

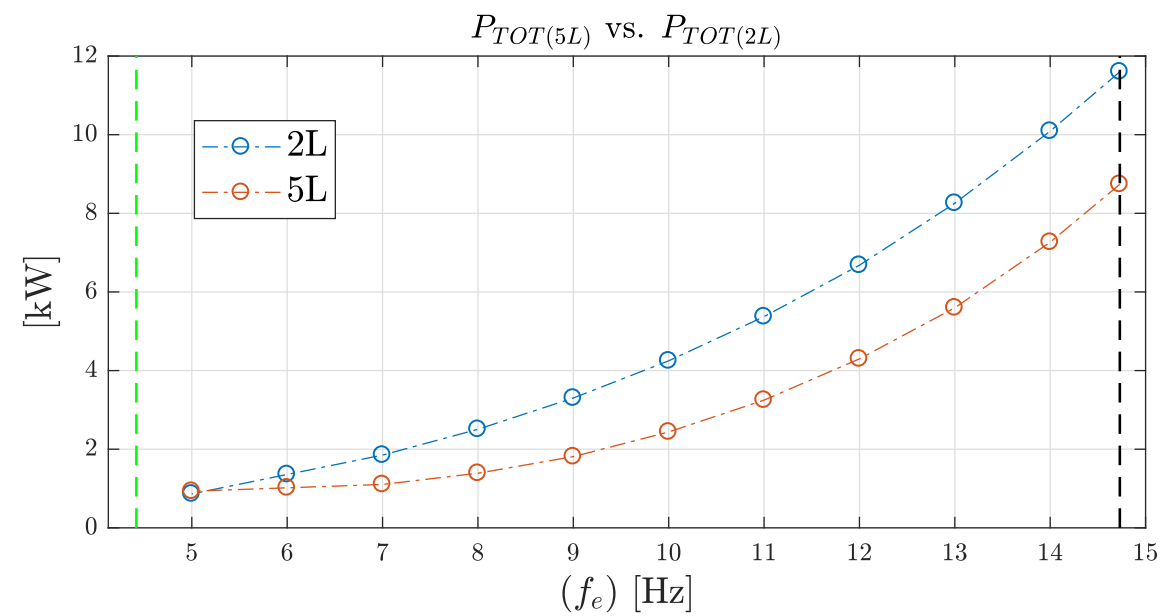

Fig. 10: Total converter losses for both topologies: 5L NPC and four two level series converters. 


\section{Conclusion}

This paper proposed a comparison between two wind energy conversion topologies: four two level converters connected in series with sequential command SPWM and a 5L NPC converter with PD PWM modulation. The WECS considered is a four modules AFPMSG directly driven by a WT. The comparison is based on simulations performed by Matlab/Simulink. Two aspects were considered in the comparison, namely harmonic content and converter losses.

The four series connected converters with sequential command offers a better overall torque waveform and dc voltage thanks to the cancellation of targeted harmonics despite more distorted phase currents than the 5L NPC one. An accurate model for the losses calculation in Matlab/Simulink was also used which calculates the converter losses every simulation instant $t_{x}$. It was shown that the losses in the four $2 \mathrm{~L}$ converters are relatively higher compared to the $5 \mathrm{~L} \mathrm{NPC}$ for all the frequency range of the WECS. However, the $2 \mathrm{~L}$ converters configuration offers higher redundancy, reliability and simplicity of gating circuits compared to the 5L NPC converter. Future work will concern experimental work for both configurations.

\section{References}

[1] A. A. Pop, M. Radulescu, H. Balan and H. Kanchev, "Electromagnetic torque capabilities of axial-flux and radial-flux permanent-magnet machines," 2013 4th International Symposium on Electrical and Electronics Engineering (ISEEE), Galati, 2013, pp. 1-4.

[2] A. Di Gerlando, G. Foglia, M. F. Iacchetti, R. Perini, ”Axial Flux PM Machines With Concentrated Armature Windings: Design Analysis and Test Validation of Wind Energy Generators," in IEEE Transactions on Industrial Electronics, vol. 58, no. 9, pp. 3795-3805, Sept. 2011.

[3] A. Di Gerlando, K. ElShawarby, G. M. Foglia, M. F. Iacchetti and R. Perini, "DC Current and Torque Ripple Mitigation in Modular PMSG Drives for Multi-MW WECSs with Linear PWM Inverter Modulation," 2018 XIII International Conference on Electrical Machines (ICEM), Alexandroupoli, 2018, pp. 1458-1464.

[4] G. Grandi, J. Loncarski, O. Dordevic: "Analysis and Comparison of Peak to Peak Current ripple in two level and multilevel PWM inverters", IEEE Trans on Ind. Electr., 2015, 62, (5), pp. 2721-2730

[5] F. Merahi, S. Mekhilef and E. M. Berkouk, "DC-voltage regulation of a five levels neutral point clamped cascaded converter for wind energy conversion system," 2014 International Power Electronics Conference (IPEC-Hiroshima 2014 - ECCE ASIA), Hiroshima, 2014, pp. 560-566.

[6] D. W. Kang and D. S. Hyun, "Simple harmonic analysis method for multi-carrier PWM techniques using output phase voltage in multi-level inverter," in IEE Proceedings - Electric Power Applications, vol. 152, no. 2, pp. 157-165, 4 March 2005.

[7] J. J. Mane, S. P. Muley and M. V. Aware, "Performance of 5-level NPC inverter with multi-multicarrier multi-modulation technique," 2012 IEEE International Conference on Power Electronics, Drives and Energy Systems (PEDES), Bengaluru, 2012, pp. 1-5.

[8] K. ElShawarby, A. Di Gerlando, G. M. Foglia and R. Perini, "DC Voltage and Torque Ripple Mitigation in Modular PMSG Drives for Off-Shore Multi-MW WECSs with Linear SPWM modulation,' submitted to EPE 19 Genova 2-6 September 2019.

[9] A.Carboni, K. ElShawarby, G. M. Foglia, R. Perini, A. Di Gerlando, E. Ragaini "Electric Stress in Power Electronics Application" ccepted for presentation in PowerTech 2019, Milano, Italy, June 23-27 2019.

[10] Pierre Giroux (2012). Loss Calculation in a Buck Converter Using SimPowerSystems and Simscape (www.mathworks.com/matlabcentral/fileexchange/35980-loss-calculation-in-a-buck-converter-usingsimpowersystems-and-simscape), MATLAB Central File Exchange. Retrieved April 03, 2012.

[11] Schütze, T. AN2008-03: Thermal equivalent circuit models. Application Note. V1.0. Germany: Infineon Technologies AG, 2008.

[12] R. Melicio, V. M. F. Mendes and J. P. S. Catalao, "Two-level and multilevel converters for wind energy systems: A comparative study," 2008 13th International Power Electronics and Motion Control Conference, Poznan, 2008, pp. 1682-1687. 